\title{
TWO MRNA SPECIES DIFFERING BY 258 NUCLEOTIDES AT THE 5' END ARE FORMED FROM THE BARLEY CHLOROPLAST rbCL GENE
}

by

CARSTEN POULSEN

Department of Physiology, Carlsberg Laboratory,
Gamle Carlsberg Vej 10, DK-2500 Copenhagen Valby

Keywords: Ribulose bisphosphate carboxylase-oxygenase, large subunit, light stimulation, transcription, promotor, plastid development

The region of the barley chloroplast genome encoding the 5' third of the rbcL gene has been subcloned in M13 vectors and sequenced by the dideoxy chain termination method. Some of the recombinant M1 3 clones have been used as a template for the synthesis of highly radioactive single stranded DNA probes. These are specifically hybridizing to short regions at the 5 ' end of the two transcripts, which were previously found to be encoded by the rbcL region in barley cpDNA. The two transcripts differ in size by more than 200 nucleotides, are encoded by the same strand and contain the full coding capacity for the large subunit of ribulose bisphosphate carboxylase-oxygenase. The short transcript is predominant in dark grown seedlings. Of two probes employed in this study one hybridized only to the long and the other to both rbcL mRNA species. Thereby it was possible to quantitate the rbcL mRNAs by hybridization with the probes and subsequent S1-nuclease digestion of the single stranded molecules. I found this mRNA to be aproximately $1.38 \%$ of total plastid RNA (excluding the small rRNAs and the tRNAs) in dark grown seedlings and $2.20 \%$ in greened seedlings. The two probes were also used in primer extension experiments using the two transcripts as template. After hybridizing the probe to the mRNA reverse transcription was performed in the presence of cold deoxynucleotides. The reverse transcribed strands were separated on sequencing gels. The probe which acted as a specific primer for the short transcript was extended by 29 nucleotides, and the probe specific for the longer transcript was extended by 91 nucleotides. The end point of the latter transcript was only found with template RNA from plastids of greened barley seedlings. Thus it was shown that the 5 ' ends of the two transcripts begin at positions -58 and -316 from the ATG triplet of the rbcL reading frame. A comparison of the sequences upstream from the ATG codon of the rbcL gene of barley with those of maize, spinach and tobacco revealed completely conserved prokaryote type transcription promotors in front of the 5 ' end of the long transcript, while no such promotors are evident close to the 5 ' end point of the short transcript. The two monocot species differ from the dicot species by an insertion of about 140 nucleotides in the mRNA leader sequence.

Abbreviations: atpB $=$ the gene for ATP synthetase $C_{\text {, }}$ subunit $\beta ;$ bp $(s)=$ basepair(s); cpDNA = chloroplast DNA; dsDNA = double stranded DNA; $k b(s)=$ kilobase(s); $k b p(s)=$ kilobasepair(s); LS = large subunit; psbA = gene for a 32,000 dalton photosystem II protein; rbcL = gene for the RuBPCase-Oase LS; RF = replicative form; RuBPCase-Oase = ribulose bisphosphate carboxylase-oxygenase; ssDNA = single stranded DNA. 


\section{l. INTRODUCTION}

The enzyme ribulose-1,5-bisphosphate carboxylase-oxygenase (RuBPCase-Oase) is found in all photosynthetic organisms, eukaryotic as well as prokaryotic. In most cases the enzyme is composed of two types of subunits, eight identical catalytic, large subunits (LS) of 52,000$56,000 \mathrm{MW}$ each and eight small subunits (SS) of $12,000-15,000 \mathrm{MW}$ a piece (21). The role of the small subunit in the assembled enzyme is still enigmatic. In green algae and in higher plants, the large subunit is encoded by a unique gene (rbcL) on the multi-copy chloroplast genome (7) whereas the small subunits are encoded by a small multi-gene family in the nuclear genome $(5,8)$. The mRNA of the large subunit gene, rbcL, is translated in the organelles. The mature $m R N A s$ of the small subunit genes are translated on cytoplasmic $80 \mathrm{~S}$ ribosomes into a polypeptide precursor which is transported across the chloroplast envelope and after removal of the N-terminal extension assembled with large subunit into mature enzyme $(4,9,29)$.

The nucleotide sequences of the genes for the subunits have revealed that the small subunit amino acid sequences differ widely among species (5) whereas the amino acid sequences of the large subunits are more strongly conserved $(6,7$, $21,28)$. Conserved domains in the small subunit are of interest in elucidating the mechanisms of transportation of the small subunit into the chloroplasts (5) and assembly of the enzyme (3, 29). In the large subunit domains of importance for the catalytic function of the enzyme are completely conserved $(20,21)$.

A comparison of the nucleotide sequences at the 5' end of the genes for the two subunits may reveal signals of importance for the concerted expression of genes in the nucleus and chloroplast. An increase in the synthesis of RuBPCaseOase protein occurs upon illumination of darkgrown seedlings of higher plants $(13,29)$. In pea light increases the transcription of the small and large subunit genes (29). In a Chlamydomonas mutant deficient in chloroplast ribosomes mRNA for the small subunit is produced at normal levels but not translated (19).

In my previous study on the in vivo transcription of the barley chloroplast DNA (22) I found that two transcripts hybridized to the region encoding the large subunit of RuBPCase-Oase. The longer transcript of 1,900 nucleotides was primarily found in RNA isolated from plastids of illuminated dark grown barley seedlings. The more than 200 nucleotides shorter transcript was found in plastids of dark grown as well as greened seedlings and in approximately equal amounts relative to the content of rRNA. In the present study I have subcloned the 5' end of the barley rbcL gene in M13 vectors and sequenced the region by the dideoxy chain termination method. Thereafter, 1 have used the single stranded recombinant bacteriophage DNA molecules as a template for the in vitro synthesis of DNA probes hybridizing differentially to the two types of mRNA. A dsDNA was synthesized using the non-transcribed strand of the gene as template and cut with EcoRI at a site close to the 5 ' end of the short transcript. After separation of the two probes they were hybridized to aliquots of plastid RNA and used to show that the two transcripts are colinear. The hybridized probes were extended by RNA-dependent DNA synthesis and thereby the 5 ' ends of the two transcripts were defined.

The amount of the two types of rbcL mRNAs in dark grown and greening seedlings is estimated. The rbcL 5' sequences of barley are compared with the corresponding sequences of maize, tobacco and spinach.

\section{MATERIAIS AND METHODS}

\subsection{Chemicals and enzymes}

All chemicals were analytical grade. The use of some enzymes has been described previously (22). In addition, the enzymes BglII, PvulI, calf alkaline phosphatase and Klenow large fragment DNA polymerase was from Boehringer, Mannheim, Germany. Accl and Hincll was from New England Biolabs, Beverly, Ma., USA. Avian myeloblastosis virus reverse transcriptase was from Life Sciences, St. Petersburg, Fla., USA and S1-nuclease was from Bethesda Research Laboratories, Bethesda, Md., USA. All enzymes were used as recommended by the companies, unless otherwise noted. The pentadecamer sequencing primer was also from New England Biolabs. Radionucleotide $\alpha-{ }^{32} \mathrm{P}-\mathrm{dATP}$ ( $>400 \mathrm{Ci} / \mathrm{mmol}$ ) was from Amersham Inter- 
national, Amersham, Buckinghamshire, England. Reagents, media and stock solutions for the selection and preparation of $\mathrm{M} 13$ recombinant clones (cf. section 2.2) were used as described by RASMUSSEN et al. (23).

\section{2. Cloning of rbcL 5' DNA}

A $1.4 \mathrm{kbp}$ PstI-BglII fragment from the barley chloroplast DNA clone pHvc209 was ligated into the PstI-BamHI sites of the filamentous phage vectors $\mathrm{M} 13 \mathrm{mp} 8$ and $\mathrm{M} 13 \mathrm{mp} 9$ (18). The replicative forms (RF) of the vectors and the resulting recombinants were prepared after infection of E. coli JM101 and further amplification as described by ZINDER and BOEKE (32). The plasmid preparation procedure employing lysozyme and alkaline SDS was used $(2,22)$. For subcloning, fragments from RF DNA of the pHvc209PBg3-clone were obtained by digestion with HinclI, AccI, EcoRI and EcoRI+PstI. First the DNA was digested with Pvull, treated with calf alkaline phosphatase, and extracted with phenol before further restriction with HincII, AccI, EcoRI, and PstI. Thereafter the fragments were ligated into the corresponding sites of either M13mp8 or M $13 \mathrm{mp} 9$ or both. Vector molecules restricted with only one enzyme were also treated with calf alkaline phosphatase, purified by phenol extraction, ethanol precipitation and gel filtration (22) before use in ligations. Fragments obtained by digestion with two enzymes were ligated directly into the vectors which had not been treated with phosphatase. Transformation of competent E. coli JM101 cells, selection of recombinant phages, preparation of phage particles from $1.5 \mathrm{ml}$ cultures and preparation of single stranded phage DNA was performed as described by other investigators $(18,23,32)$. The DNA was dissolved in $10 \mu 110 \mathrm{~mm}-\mathrm{Tris}-\mathrm{HCl} \mathrm{pH}$ $7.5,1 \mathrm{~mm}$-EDTA and frozen $\left(-20^{\circ} \mathrm{C}\right)$ until needed.

\subsection{Nucleotide sequencing and gel electrophoresis}

Nucleotide sequencing of aliquots of the single stranded M13 recombinant DNA molecules was performed by the dideoxy chain termination technique according to SANGER et al. (25).
Gel electrophoresis of samples, after S1-nuclease treatment or reverse transcription was performed on $6 \%$ polyacrylamide gels (19: 1 bis) containing $7.3 \mathrm{M}$-urea. The gels were fixed, dried and autoradiographed as described by RASMUSSEN et al. (23).

\subsection{Chloroplast RNA}

Isolation of RNA from etiolated plastids and eight hour greened plastids was as described previously (22). The concentration of the rRNA species in the two stock samples was the same and the approximate total RNA concentration was $3 \mu \mathrm{g} \times \mathrm{ml}^{-1}$.

\subsection{Preparation of hybridization probes}

One picomole of the pentadecamer sequencing primer was annealed to $2 \mu \mathrm{g}(0.8 \mathrm{pmol})$ of single stranded $\mathrm{pHvc} 209 \mathrm{PBg} 3$ dissolved in $10 \mu \mathrm{l}$ of $10 \mathrm{~mm}$-Tris- $\mathrm{HCl} \mathrm{pH} \mathrm{7.4,10} \mathrm{mM-} \mathrm{MgCl}_{2}, 50$ $\mathrm{mM}-\mathrm{NaCl}$ and sealed in a glass capillary. The capillary was heated to $90^{\circ} \mathrm{C}$ in a waterbath for five minutes, transferred to a $67^{\circ} \mathrm{C}$ waterbath and incubated for 30 minutes. Thereafter the waterbath was allowed to cool to room temperature overnight. The contents of the capillary was emptied into an Eppendorf tube containing 10 $\mu l$ of a solution being $0.1 \mathrm{~mm}$ in the three deoxynucleotides dGTP, dCTP and TTP and also containing $200 \mu \mathrm{Ci}$ of $\alpha-{ }^{32} \mathrm{P}$-dATP (400 $\mathrm{Ci} / \mathrm{mmol}$ corresponding to 500 pmoles and a final concentration of $25 \mu \mathrm{M}$ ). After addition of 2.5 units of Klenow large fragment DNA polymerase synthesis of doublestranded DNA (dsDNA) was allowed for 30 minutes. The reaction was chased with one $\mu \mathrm{l}$ of $0.5 \mathrm{mM}$ dATP and another 2. 5 units of Klenow large fragment was added as well. DNA synthesis continued for another 30 minutes. The DNA was precipitated and the pellet washed with $70 \%$ (v/v) ethanol several times, until only small amounts of radioactivity could be detected in the supernatant. The DNA was dried, resuspended in $100 \mu \mathrm{l}$ of EcoRI buffer, digested with 10 units of EcoRI and subsequently reprecipitated. To separate the radioactive probes from the template restricted DNA was dissolved in $100 \mu \mathrm{l}$ of $30 \%(\mathrm{v} / \mathrm{v})$ DMSO, 1 mM-EDTA pH 8, 0, 0.05\% 
$(\mathrm{w} / \mathrm{v})$ bromphenol blue, $0.05 \%(\mathrm{w} / \mathrm{v})$ xylene cyanol, treated at $90^{\circ} \mathrm{C}$ for three minutes and quickly cooled to $0{ }^{\circ} \mathrm{C}$. The denatured sample was applied to a $400 \times 150 \times 1.5 \mathrm{~mm} 5 \%$ polyacrylamide gel (50:1 bis). Electrophoresis buffer was 50 mM-Tris-borate pH 8.3, 1 mM-EDTA. After electrophoresis for 20 hours at $250 \mathrm{~V}$ and detection of radioactive bands on X-ray film, gel slices containing single stranded radioactive DNA were excised and eluted (22). Ten $\mu \mathrm{g}$ of yeast RNA was added to the eluate and the single stranded DNA was purified by phenol extraction and gel filtration on spin columns of Sephadex G-50 (22). At this stage, an aliquot of the solution was taken for determination of yield by liquid scintillation counting (22). After subsequent ethanol precipitation and drying the DNA was dissolved in $20 \mu \mathrm{l}$ of sterile water and frozen $\left(-20^{\circ} \mathrm{C}\right)$ until required for further use.

\subsection{DNA-RNA hybridizations}

The single stranded radioactive DNA probes were hybridized to aliquots of barley plastid RNA in the following way: Two $\mu$ l of DNA (cf. section 2.5) was mixed with the RNA and dried in a Savant Speedy-Vac. The dry nucleic acids were redissolved in $10 \mu \mathrm{l}$ of sterile $40 \mathrm{~mm}$ Pipes-NaOH pH 6.4, 1 mM-EDTA, $0.4 \mathrm{M}-\mathrm{NaCl}$. This mixture was sealed into sterile glass capillaries and heated for 15 minutes in a glass beaker containing boiling water. The beaker was transferred to a $67^{\circ} \mathrm{C}$ waterbath, whereafter hybridization was taking place for 12 hours. After hybridization the capillaries were cooled to $0^{\circ} \mathrm{C}$. The contents could then be used for S1-nuclease digestion or reverse transcription (cf. sections 2.7 and 2.8).

\subsection{S1-nuclease digestions}

Five of the $10 \mu \mathrm{l}$ of hybridization mixture were diluted with $90 \mu \mathrm{l}$ of ice-cold S1-nuclease buffer ( $50 \mathrm{~mm}$-Na-acetate $\mathrm{pH} 4.6,4.5 \mathrm{mM}-\mathrm{ZnSO}_{4}, 0.28$ $\mathrm{M}-\mathrm{NaCl}, 20 \mu \mathrm{g} \times \mathrm{ml}^{-1}$ of hybridization grade salmon sperm DNA (22)). Twenty units of S1-nuclease was added and the samples incubated at $37{ }^{\circ} \mathrm{C}$ for 30 minutes. Five $\mu$ l of 0.5 $\mathrm{M}-E D T A \mathrm{pH} 7.5,10 \mu \mathrm{l}$ of $3 \mathrm{M}-\mathrm{Na}$-acetate and one $\mu \mathrm{l}$ of $10 \mathrm{mg} \times \mathrm{ml}^{-1}$ yeast RNA was added and the samples precipitated with $300 \mu 1$ of ethanol. Nucleic acid pellets were washed twice with $70 \%$ (v/v) ethanol and dried. Radioactivity was determined by Cerenkov-counting. Subsequently, samples were dissolved in $80 \%$ formamide, 0.1 M-Tris-borate $\mathrm{pH}$ 8.3, 2 mm-EDTA, $0.05 \%$ $(\mathrm{w} / \mathrm{v})$ bromphenol blue, $0.05 \%(\mathrm{w} / \mathrm{v})$ xylene cyanol (formamide-dye buffer). After precipitation and drying the radioactivity of the remaining five $\mu \mathrm{l}$ of hybridization mixture was determined by Cerenkow-counting. Also these samples were dissolved in the formamide-dye buffer. Aliquots were then electrophoresed on $6 \%$ polyacrylamide sequencing gels employing suitable size markers.

\subsection{Primerextension with reverse transcriptase}

Ten $\mu$ l of radioactive DNA/RNA hybridization mixtures was combined with $10 \mu \mathrm{l}$ buffer in sterile Eppendorf tubes. The buffer contained 0.1 M-Tris- $\mathrm{HCl} \mathrm{pH} \mathrm{8.3,4mM-DTT,} 10 \mathrm{~mm}^{-}$ $\mathrm{MgCl}_{2}, 80 \mathrm{mM}-\mathrm{KCl}$ and was also $0.5 \mathrm{mM}$ in the four deoxynucleotides dGTP, dCTP, dATP and TTP. RNA-dependent DNA synthesis was obtained after the addition of one $\mu$ l containing 12 units of reverse transcriptase and subsequent incubation at $37{ }^{\circ} \mathrm{C}$ for one hour (9). The reaction mixtures were rapidly cooled to $0{ }^{\circ} \mathrm{C}$ and $10 \mu \mathrm{l}$ was removed and subjected to $\mathrm{S} 1$-nuclease digestion (cf. section 2.7). One $\mu$ l of 0.5 M-EDTA pH 7.5 and $100 \mu \mathrm{l}$ of $0.3 \mathrm{M}$-Na-acetate was added to the remaining $11 \mu \mathrm{l}$ of reverse transcription mixture. The nucleic acids were precipitated with ethanol and the pellets washed with $70 \%(\mathrm{v} / \mathrm{v})$ ethanol as described above and then subjected to gel electrophoresis on $6 \%$ polyacrylamide sequencing gels.

\section{RESULTS}

3.1. Cloning and sequencing of the rbcL 5' end

The barley chloroplast DNA clone pHvc209 has previously been found to contain parts of the rbcL gene (22). A detailed physical map of the plasmid is shown in the upper half of Figure 1. Previously mapped restriction sites for PstI (the cloning site), BamHI and SalI are shown together with the sites found for BglII, EcoRI and HindIII. The rbcL mRNA is transcribed from 


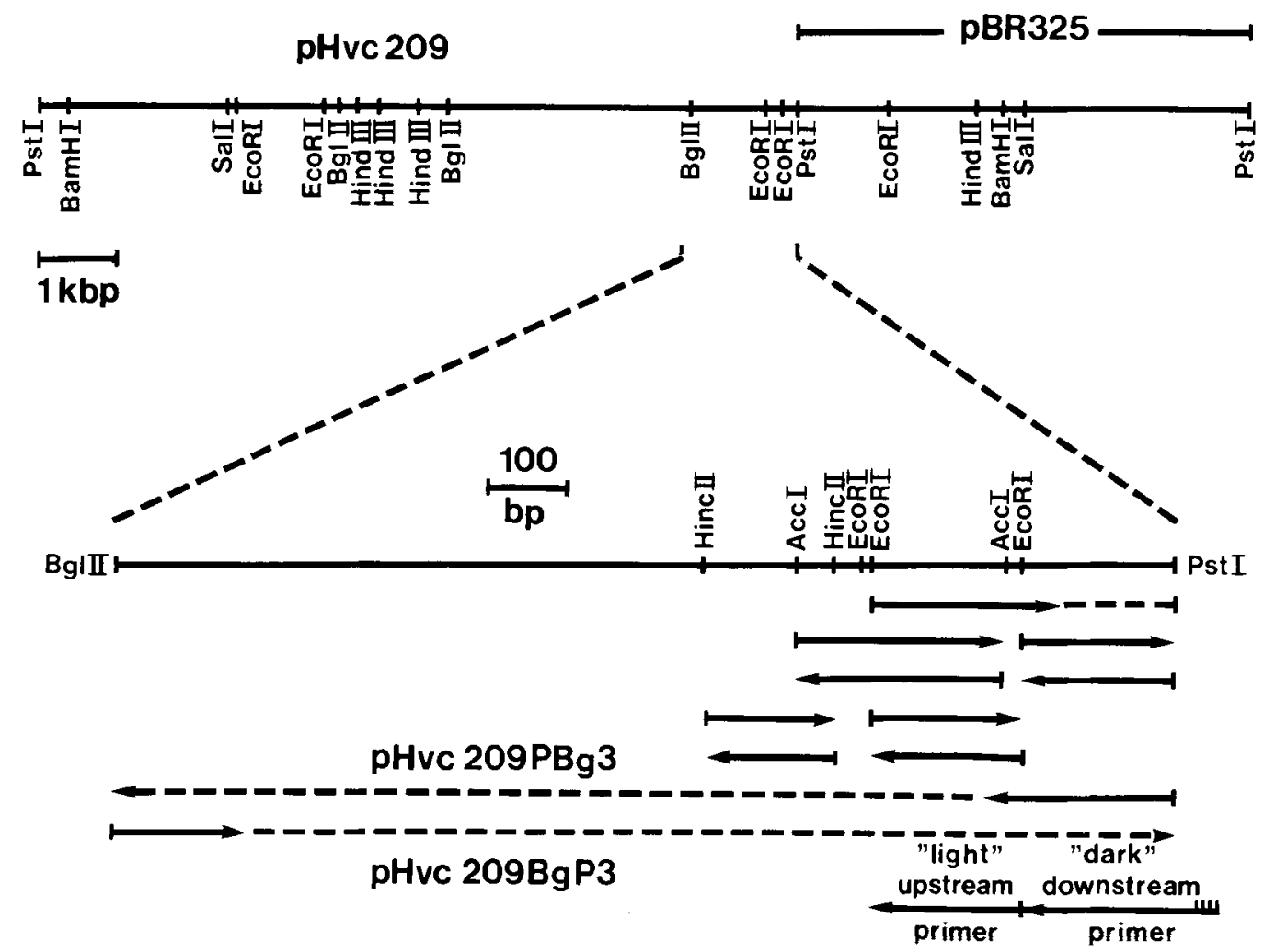

Figure 1. Physical map of the barley chloroplast DNA clone pHvc209. The $10 \mathrm{kbp}$ Pstl fragment cloned in pBR325 has been described previously (22). The indicated $1.4 \mathrm{kbp}$ Pstl-Bglll fragment was cloned in M13mp8 and in $\mathrm{M} 13 \mathrm{mp} 9$ resulting in the clones pHvc209PBg3 and $\mathrm{pHvc} 209 \mathrm{BgP}$, respectively. Further subclones were obtained by digesting the pHvc209PBg3 RF DNA with PvuII and calf alkaline phosphatase, followed by either EcoRI, HincII, AccI or EcoRI+PstI. Resulting fragments were ligated into restricted and phosphatase treated vectors. Single strand recombinant DNA molecules were obtained after transformation, phage propagation, phage isolation and phenol extraction. Direction and extension of the nucleotide sequences determined with the dideoxy chain termination method are shown with full arrows. See text for further detail.

the right hand side of the $\mathrm{pHvc} 209$ insert and the rest of the transcript is encoded by the neighboring PstI fragment of the barley cpDNA. The 1.4 kbp Pstl/BglII fragment was subcloned into the PstI/BamHI sites of M13mp8 and M13mp9. After isolation of DNA from recombinant phages, sequences of 200-250 nucleotides of the insert DNA were obtained. Comparison of the sequences with the corresponding maize cpDNA sequences (17) revealed that the PstI site of the subclone pHvC209PBg3 is located 167 bps downstream from the ATG start codon of the rbcL gene. The subclone pHvC209BgP3 gave a sequence at the 5 ' end of the complementary strand. The BgIII site corresponds to the
BglII site found at position +410 in the maize atpB gene (15). The sequences obtained from both clones were highly homologous to the maize sequences.

After isolation of replicative form (RF) DNA of $\mathrm{pHvc} 209 \mathrm{PBg} 3$ the insert DNA was subcloned in either $\mathrm{M} 13 \mathrm{mp} 8$ or M13mp9 or both employing the available PstI, EcoRI, AccI and HincII sites (Figure 1, lower half). The pHvc209PBg3 RF DNA was cleaved with PvulI prior to cutting with the other endonucleases and subcloning. Pvull fragments the M13mp8 and M13mp9 molecules at three sites, but does not cut the insert sequence. Thereby background transformation with the religated original recombinant 
HincII

XXXAACAAAGAATTTTATTAGTATTTAG-TTAGGTA----TTTGCATTCCAAATAA-_-_-_-gAAAA---GAGACC-TATTAAG GTCAACAGAGAATTTTCTTAGTATTT-----AGGTA----TTTAGATTCAAAATAT-------CAAAGGGGAGAAC--TTTAAA GTCAAGGGGGAAG-TTCTTATTATTTAGGTTAGTCAGGTATTT-

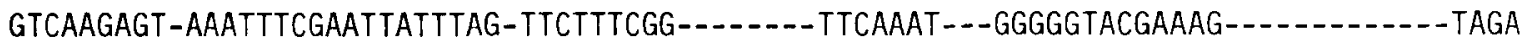

$$
\begin{array}{lll}
-359 & -350 & -316
\end{array}
$$

AACTTGTAAAA--TAAGGATTAGGGATTAATTTGGGTTGCGCTATACCTATCAAAGAGTATACAATAATGATGGATTTGGTAAATC $-350$ $-300$

AA-TTGTAAAA--TAAAGATTAGGG--.--TTTGGGTTGCGCTATATCTATCAAAGAGTATACAATAATGATGGATTTGGTGAATC AA----AAAAAAAAGTAAAAAAGAAAAA-TTGGGTTGCGCTATATATATGAAAGAGTATACAATAATGATGTATTTGGCAAATC AACTTGAAAACCAA--CGGTTACGG-.--TTGGGTTGCGCCATATATATGAAAGAGTATACAATAATGATGTATTTGGCGAATC $-300 \quad-278$ HincII $-250 \quad$ ECORI ECORI* AAAT-CCATGGTTTAATAACGAACCGTGTTAACTTACCATAACAACAACTCAATTCCTATCGAATTCCTATAGTGGAATTCCTATA $-250$

AAAT--CACGGTTTAATAACGAACCGTGTTAACTTACCATAACAACAACTCAATTCCTATCGAATTCCTATAGTAAAATTCCTATA $-150$

AAATACCATGGTCTAATAATCAAACAT

$$
-150 \quad-140
$$

AAATA-CATGGTCTATTAACGAACCAT-

GgATAGAACATACACAGgGTGTACGCATtATATATGAATGAAACATATTCATTAACCTAAgCATGCCCTCAATTTTCTTTAATGAG $-200$ $-150$

GGATAGAACGTACACAGGGTGTATAC---ATAAATGAATCAAACATATTACTTAACTTAAGCATACTCCTTTTTTTATTTAATGAG

TTGATATTAT--- ATTAATTGAATATCCTTTTTGTTTTACGAGATT--TITGCTAAAG-TTTCATTTACGCCTAATTAACATCGA

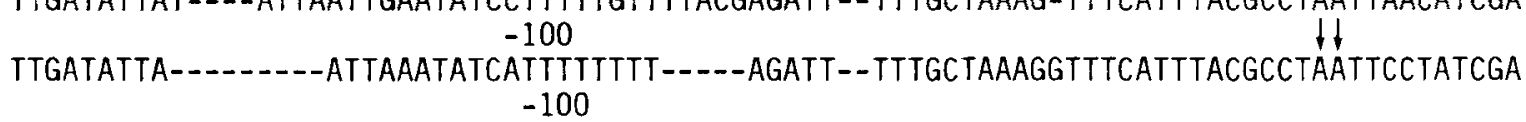

TTGATAATATTAGTATTAGTTGGAAA--TTTTGTG-----AAAGATTCCTATG--AAAAGTTTCATTAACACGGAATTCGTGTCGA $-100$

TTGATAATATTA--ATT----GAGAA--TTTGATG-----AAAGATTGCTATA--AAAGGTTTCATTAAGGCCTAATTTATGTCGA

ACCI ECORI*

GTAGACCCTGTTA--TTGT-GAGAATTCTTAA--TTCAAG-AGTTGTAGgGAgGGACTT ATG Barley

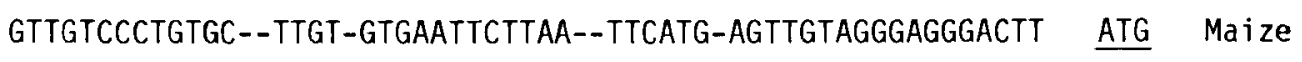

GTAGACCTTGTTG--TTGT-GAGAATTCTTAA--TTCATG-AgTTGTAGgGAGGGATTT ATG Tobacco

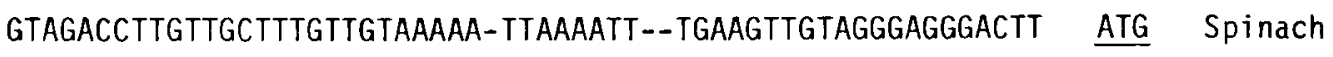


M13 DNA molecule could be eliminated. The inserts of the resulting recombinant phage DNA molecules were sequenced yielding a contiguous sequence of about $600 \mathrm{bp}$ proximal to the PstI site of pHvc209PBg3. The sequence covering the region from the ATG start codon to the Hincll site at -452 is presented in Figure 2 together with the homologous regions of the maize (17), spinach (35) and tobacco (27) cpDNAs. In the maize gene both HincII sites, one out of two AccI sites and two out of three EcoRI sites are found in positions homologous to those of the barley gene.

One of the EcoRI/PstI clones was found to result from incomplete EcoRI cleavage, whereby an insert of 393 nucleotides rather than one of 198 nucleotides was obtained. This clone was useful for sequencing the overlap of the AccI and EcoRI sites proximal to the PstI site (Figure 1).

\subsection{In vitro synthesis of radioactive probes for hybridization and primer extension}

In an early attempt to define the direction of transcription of the two transcripts derived from the rbcL region of the barley chloroplast genome, the following experiment was carried out: From the pHvc209PBg3 RF DNA a small $195 \mathrm{bp}$ EcoRI fragment was isolated. The fragment was 5 ' end labelled with $\gamma-{ }^{32}$ P-ATP and polynucleotide kinase. The strands were separated by polyacrylamide gel electrophoresis, eluted from the gel and purified by precipitation with $\mathrm{Na}$-acetate and ethanol. The two isolated strands were hybridized to plastid RNA isolated from dark grown and greened plant material. Single stranded nucleic acids were digested with S1-nuclease according to BERK and SHARP (1). After gel elèctrophoresis on polyacrylamide sequencing gels and autoradiography the following observations were made: only one strand hybridized to RNA in such a way that the 5' label remained attached to polynucleotide material. Employing plastid RNA $(6 \mu \mathrm{g})$ isolated from greened plants the probe hybridized to the mRNA, in such a way that the entire length of the DNA molecules which hybridized to the mRNA was resistant to SI-nuclease digestion. With plastid RNA $(6 \mu \mathrm{g})$ isolated from dark grown plants, a ladder of radioactive bands corresponding to oligonucleotides of about 30 bases and less was predominant. Furthermore, this RNA did not protect the major portion of the DNA from degradation. With the knowledge that the previously determined 5' end of a maize rbcL gene transcript is located at -65 (17), and supported by the sequence homology between maize and barley in this region (Figure 2) it can be concluded that both transcripts from the barley $\mathrm{rbcL}$ gene region encode the LS reading frame and that the larger one is at least 160 nucleotides longer than that found for maize. The 5' end of the maize transcript covers 30 nucleotides of the EcoRI fragment in question. It is therefore likely that the ladder of bands observed with the barley fragment was the result of inefficient protection against S1-nuclease over a stretch of about 30 nucleotides primarily seen with plastid RNA from etiolated barley seedlings. The short barley transcript seems therefore to correspond to the maize LS mRNA studied. In order to test colinearity and precise length of the two barley transcripts, two radioactive probes hybridizing differentially to the two mRNA species were synthesized as outlined in Figure 3 . The regular pentadecamer sequencing primer was hybridized to the single stranded DNA (ssDNA) of the recombinant phage pHvc209PBg3 and used as starter to synthesize a complementary DNA strand. The synthesis was extended across the Pstl site in the coding region of the rbcL gene to a point beyond the

Figure 2. Comparison of non coding region upstream from the $\mathrm{ATG}^{\mathrm{Mct}}$ triplet in the rbcL gene of the four higher plants barley, maize (17), tobacco (27) and spinach (35). The 5' end of the barley rbcL transcript specific for greened seedlings is indicated with $\nabla$ and that found also in dark grown seedlings with $\nabla$. The 5 ' ends of known rbcL transcripts from the other three species are indicated with $\downarrow$. The numbers above the sequences indicate distance in nucleotides upstream (-) from the ATGs. The putative promotors for the genes are underlined and further designated by "-10" and "-35". The asterisks indicate the nucleotide complementary to the 3' end of the the two primers used in the experiments described in sections 3.2 and 3.3 . 


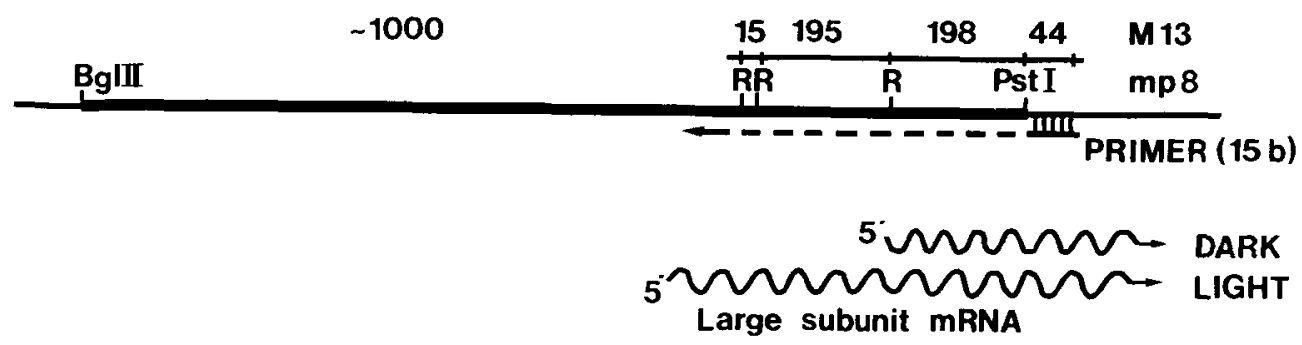

$\frac{\text { dNTP }}{\begin{array}{l}\alpha-32 \mathrm{p} \\ \text { d ATP }\end{array}} \underset{\text { polym. }}{\stackrel{\text { KAENOW }}{\text { chase }}} \frac{\text { restrict }}{\text { EcoRI }} \frac{\text { separate }}{\text { primers"D","L" }} \frac{\text { hybridize "D" } \& " L}{\text { to plastid RNA }} \frac{\text { reverse }}{\text { transcribe }} \frac{\text { gel }}{\text { electrophoresis }}$

"DARK" PRIMER

"LIGHT" PRIMER

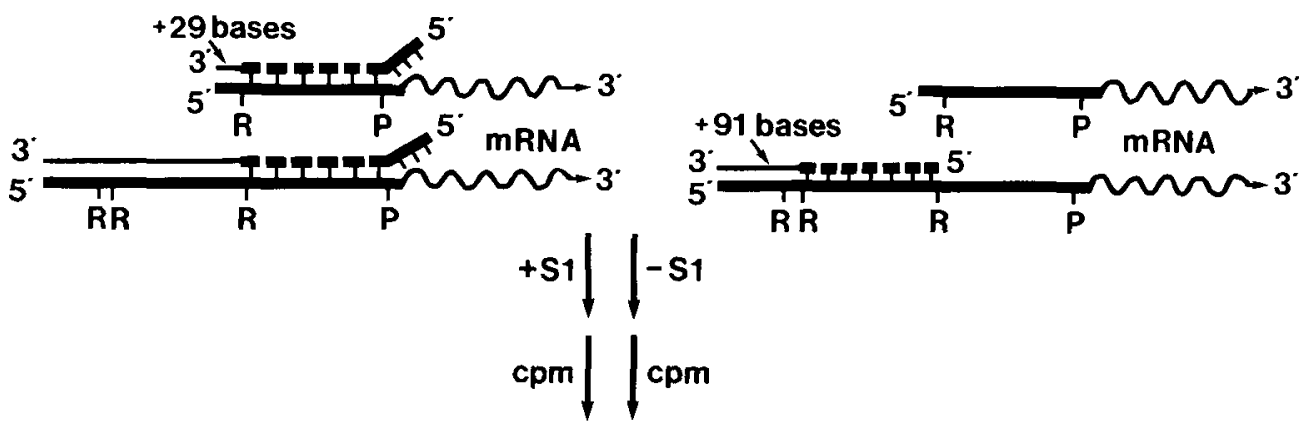

Figure 3. Scheme for the synthesis and isolation of single stranded highly labelled probes hybridizing specifically to the two transcripts coding for the large subunit (LS) of ribulose bisphosphate carboxylase-oxygenase. The probes were subsequently used as internal primers for extension with reverse transcriptase, $R=E c o R I, P=$ PstI, SI = Sl-nuclease.

three EcoRI sites (Figure 3) known to be within the 5' end of the longer mRNA species. The Klenow large fragment DNA polymerase and $\alpha-{ }^{32} \mathrm{P}-\mathrm{dATP}$ was used to ensure that a very large number of adenines were radioactive and that these were only incorporated into the newly made strand. Digestion of the dsDNA with EcoRI was followed by separation of the radioactive dsDNA molecules from the non-radioactive strands on polyacrylamide gels. This resulted in two probes designated "Light" and "Dark". The "Dark" probe consists of the 198 bp EcoRI/ Pst I fragment attached to the 29 bases separating the pentadecamer sequencing primer from the PstI site and the primer itself, i. e. an addition of 44 extra nucleotides. The "Light" probe consist of the radioactive strand of the adjacent 195 bp EcoRI fragment.
The result described above indicated that the EcoRI site separating the $195 \mathrm{bp}$ fragment from the $198 \mathrm{bp}$ Pstl-EcoRI fragment is very close to the 5' end of the shorter transcript. Thus, the radioactive 195 base sequence is expected to hybridize almost exclusively to the large transcript, which is found in plastids of greened seedlings only. The 198 bases of the other probe should hybridize equally well with both transcripts. With incorporation of ${ }^{32} \mathrm{P}$ of known specific activity it is possible to calculate the precise amount of probe used in individual hybridization experiments and permits quantitation of the two transcripts (cf. section 3.4).

A major problem in the use of the synthetic and very highly radioactive probes as primers for extension is isotope decay. The short decay time of ${ }^{32} \mathrm{P}$ will lead to frequent decompositions 
of the polynucleotide backbone 5' to the adenines. This decay will be random whereby the decay product molecules will appear as background bands on the autoradiograms. This is further discussed in section 3.3.

\subsection{Extension of radioactive DNA-primers hybridized to plastid RNA}

The two $\alpha-{ }^{32} \mathrm{P}-\mathrm{dA}$ labelled single stranded probes were hybridized to plastid RNA and then extended by reverse transcriptase. As depicted in Figure 3 different results are expected with the two probes: The "Light" primer can only be extended, if the long mRNA of greened seedlings serves as template, while both long and short mRNA can serve as template for extension of the "Dark" primer.

An example of the result obtained with the "Dark" primer is shown in Figure 4. In the left three lanes of the sequencing gel the un-extended primer and the primer extensions using mRNA of dark grown and greened seedlings have been applied. The position of the un-extended primer of 242 nucleotides is revealed in lane 0 which contains a sample after attempted extension without added plastid RNA. Lane D contains reverse transcriptions of about $5 \mathrm{ng}$ of primer hybridized to $0.75 \mu \mathrm{g}$ of plastid RNA from dark grown seedlings. A prominent band is located at the 271 mark, i. e. an extension of 29 nucleotides was obtained. Lane $\mathrm{L}$ contains reverse transcriptions of $5 \mathrm{ng}$ of the same primer hybridized to $0.75 \mu \mathrm{g}$ plastid RNA from barley seedlings greened for 8 hours. Also in this case the primer was extended by 29 nucleotides and the quantity of extended strands does not differ significantly from that obtained with RNA from dark grown plants, suggesting that the amount of this transcript is similar in dark grown or greened seedlings. The length of the extensions were determined with the aid of the three dideoxy sequencing lanes (the A-lane is absent and some unspecific chain termination has occurred). A sequence derived from pHvc209PBg3 ssDNA was hybridizing to the mRNA 5' end. It contains the complementary Shine-Dalgarno (CSD) sequence 5'-CCCTCCC3' found a few nucleotides upstream from the reading frames of rbcL mRNA. In addition to

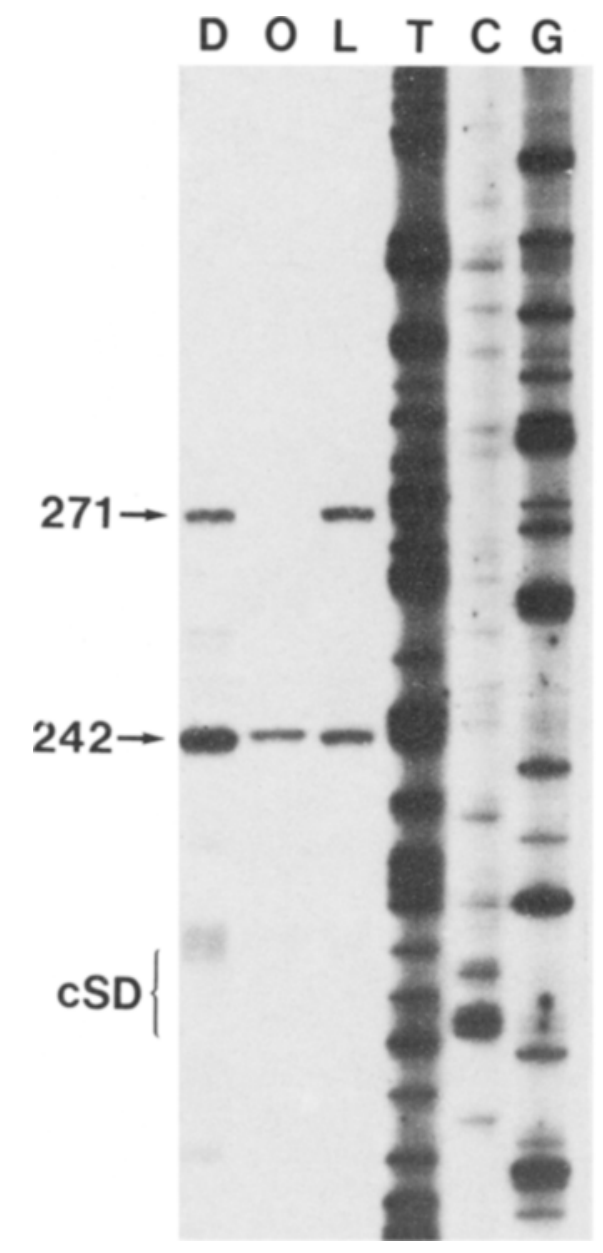

Figure 4. Extension with reverse transcriptase of the downstream 242 base "Dark" primer in hybrids with $\mathrm{rbcL}$ mRNA. The lanes $\mathrm{D}, \mathbf{0}$, and $\mathrm{L}$ show primer extensions using D: $0.75 \mu \mathrm{g}$ plastid RNA from dark grown barley seedlings; 0 : No plastid RNA; L: 0.75 $\mu \mathrm{g}$ plastid RNA from eight hour greened barley seedlings. Used as size markers the lanes $T, C$ and $G$ are dideoxy chain termination sequence reactions performed on the ssDNA of the clone pHvc209PBg3. The position of the sequence complementary to the rbcL mRNA Shine Dalgarno sequence is indicated (cSD).

the main bands at the 242 and 271 positions some background bands are seen. These must be derived from the decay products of the radioactive primer. They hybridize to the RNA and are apparently extended by reverse transcriptase. Such extensions are seen in Figure 4, 


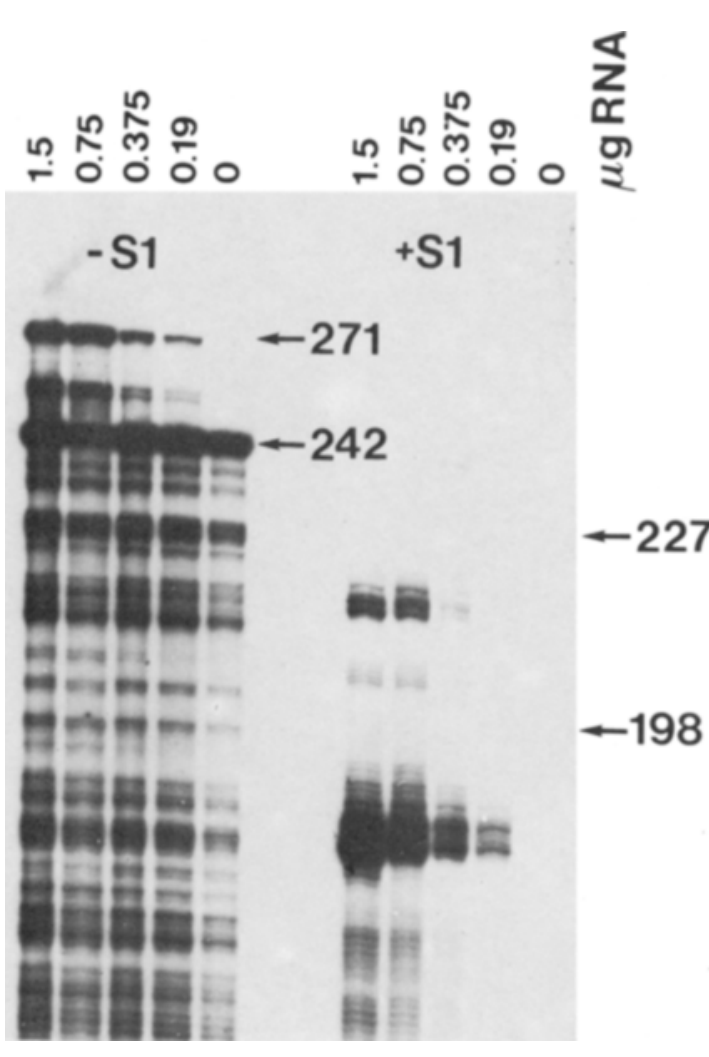

Figure 5. SI-nuclease sensitivity of hybrids between rbcL mRNA and extended primer. Extension of the 242 base primer using varying amounts of plastid RNA from dark grown seedlings as template are shown in the five left lanes. Five lanes to the right show the results of S1-nuclease digestion of the same primer extended samples. The position of the 242 base primer and its extension with 29 nucleotides (27l) are indicated. By SI-nuclease digestion the removal of the 44 base 5 ' extension on the 242 base primer and on the 271 base reverse transcription product will result in ssDNA molecules of 198 nucleotides (un-extended) and 227 nucleotides (extended).

lane $\mathrm{D}$ and lane $\mathrm{L}$, as weak bands between the 242 and the 271 marks.

Figure 5 shows that the extensions from the 242 base primer are dependent on the amount of RNA used and that the extended DNA strands are faithful copies of the rbcL RNA. In five glass capillaries $10 \mathrm{ng}$ of 242-primer was hybridized to the indicated amounts of plastid RNA from dark grown seedlings. After the hybridizations the five mixtures were reverse transcribed and subsequently divided into two halves. One half was precipitated with ethanol, dried and resuspended in formamide-dye buffer. The other half was subjected to S1-nuclease digestion, the S1-nuclease resistant material ethanol precipitated, dried and these samples were also dissolved in formamide-dye buffer. After denaturation aliquots of the 10 samples were electrophoresed on a sequencing gel. As illustrated in Figure 5, primer extension only took place in the presence of plastid RNA. In the five lanes to the left $(1.5 ; 0.75 ; 0.375 ; 0.19 ; 0 ;-S 1)$ the quantity of extended primer increases with increasing amounts of plastid RNA. In the five corresponding $+\mathrm{S} 1$ lanes the extended as well as the un-extended DNA primers of the RNADNA hybrids are found to be S1-nuclease sensitive in an RNA concentration dependent manner. It should be noted that the hybridized primer as well as extended primer have been shortened by more than the 44 nucleotides of the M13mp8 sequences (cf. Figure 3) expected not to base-pair with the mRNA. The shortening is, however, less than 60 nucleotides. This must be due to S1-nuclease sensitivity at one or both ends of the hybridized primer. The reasons for this is unclear, but similar experiments carried out in this laboratory suggest that the S1-nuclease assay temperature can be a critical factor (dr. S. HolmberG, personal commun.).

The 5' end of the longer transcript was mapped using the 195 nucleotide "Light" primer. The results are shown in Figure 6. The experiments were carried out as described for the 242 nucleotide "Dark" primer and the same rbcl gene stretch was used as a size marker. The band of the 195 nucleotide primer is seen at the middle $T$ of the sequence 5'TTTCTGTTT-3'. After hybridization and reverse transcription, extension could only be observed where the primer had been hybridized to plastid RNA from greened seedlings (lane L). The end point of the extension is 286 nucleotides away from the 5 ' end of the pentadecamer sequencing primer, i. e. a specific extension of the radioactive 195 nucleotide primer by 91 nucleotides was achieved. It is obvious that the extension in this case is far less efficient than that observed with the 242-primer in the previous experiments. This must be due to the 


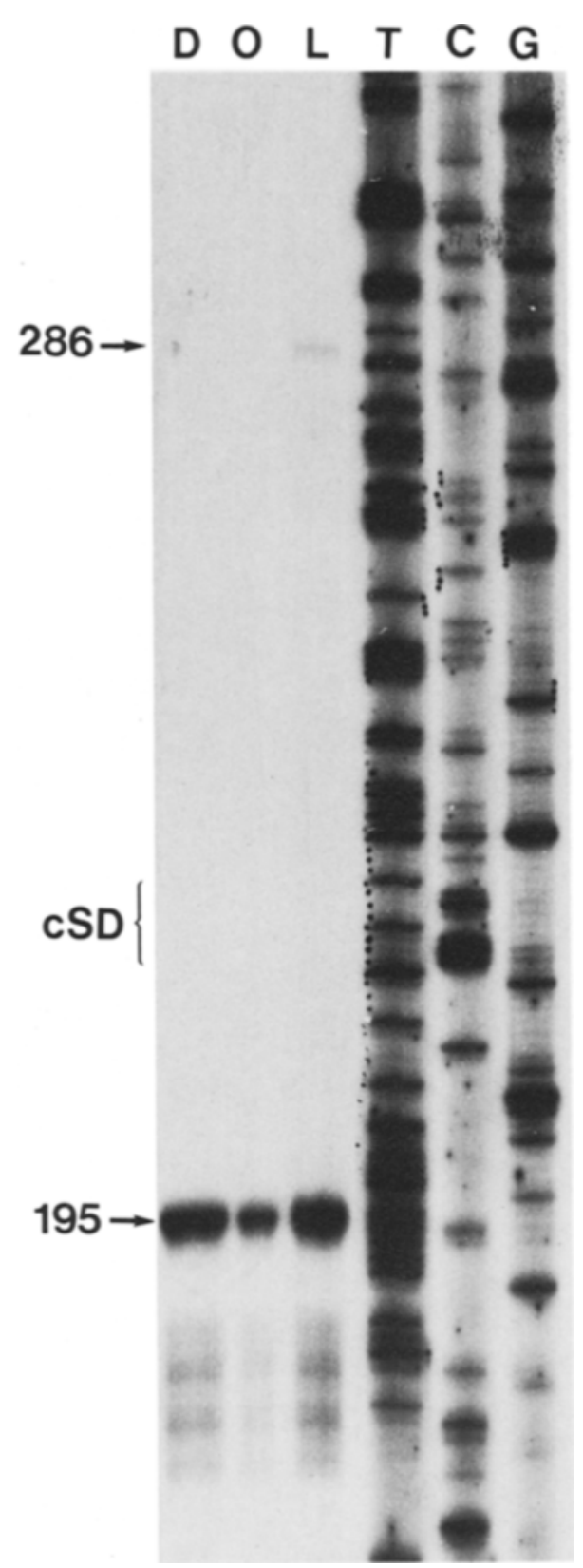

Figure 6. Extension employing the 195 base primer hybridizing specifically to the long rbcL mRNA. The positions of the primer and its extension resulting from reverse transcription of hybrids of the primer with 0.75 $\mu \mathrm{g}$ plastid RNA from greened seedlings are indicated. See legend to Figure 4 for further detail.

fact that the larger light specific transcript is found in smaller quantities than the shorter transcript. The Northern experiments conducted previously for the rbcL region support this observation.

It is possible to use extensively labelled primers made by in vitro replication rather than end labelled primers for transcript mapping. From the barley rbcL gene two transcripts are formed of which the longer one in the present experiments was found only in plastids from greened seedlings.

\subsection{Titration of LS mRNA employing S1-nuclease digestion of ${ }^{32}$ P-DNA/RNA hybrids}

In vitro synthesis and gel electrophoretic isolation of the 242 base "Dark" primer and the 195 base "Light" primer, yielded routinely preparations with more than $10^{7} \mathrm{cpm}$ of radioactivity. The two primers contain 54 and 74 adenine deoxy-nucleotides, respectively. Employing $\alpha$ ${ }^{32} \mathrm{P}$-dATP of $400 \mathrm{Ci} / \mathrm{mmol}$ and the known nucleotide content the exact yield of a probe can be calculated. In the experiment described in this section probes of $3.6 \times 10^{7}$ and $4.8 \times 10^{7} \mathrm{cpm}$ were obtained, i. e. 16.2 and $21.6 \mu \mathrm{Ci}$ are found in the two probes. Thus, $40.5 \mathrm{pmol} \mathrm{dA}$ was found in the isolated 242 base probe, corresponding to $0.75 \mathrm{pmol}$ probe and, $54.0 \mathrm{pmol} \mathrm{dA}$ was found in the 195 base probe, corresponding to 0.73 pmol probe. Each probe was used for nine simultaneous hybridizations to different amounts of plastid RNA from dark grown or eight hour greened barley seedlings and for one control without plastid RNA. Thus, $0.075 \mathrm{pmol}$ and $0.073 \mathrm{pmol}$ of the probes were used for a single hybridization. After hybridization, the 20 samples were divided in two halves, of which one was digested with 20 units of SI-nuclease. Subsequently all samples were precipitated and the pellets washed with ethanol as previously described, dried and then subjected to Cerenkov counting. Aliquots were run on polyacrylamide sequencing gels after denaturation in formamide-dye buffer in order to confirm the extent of S1-nuclease protection of the probes as presented in section 3. 3. Except for the removal of slightly more than 44 nucleotides from the 242 base probe, this was found to be the case.

The degree of protection against S1-nuclease 


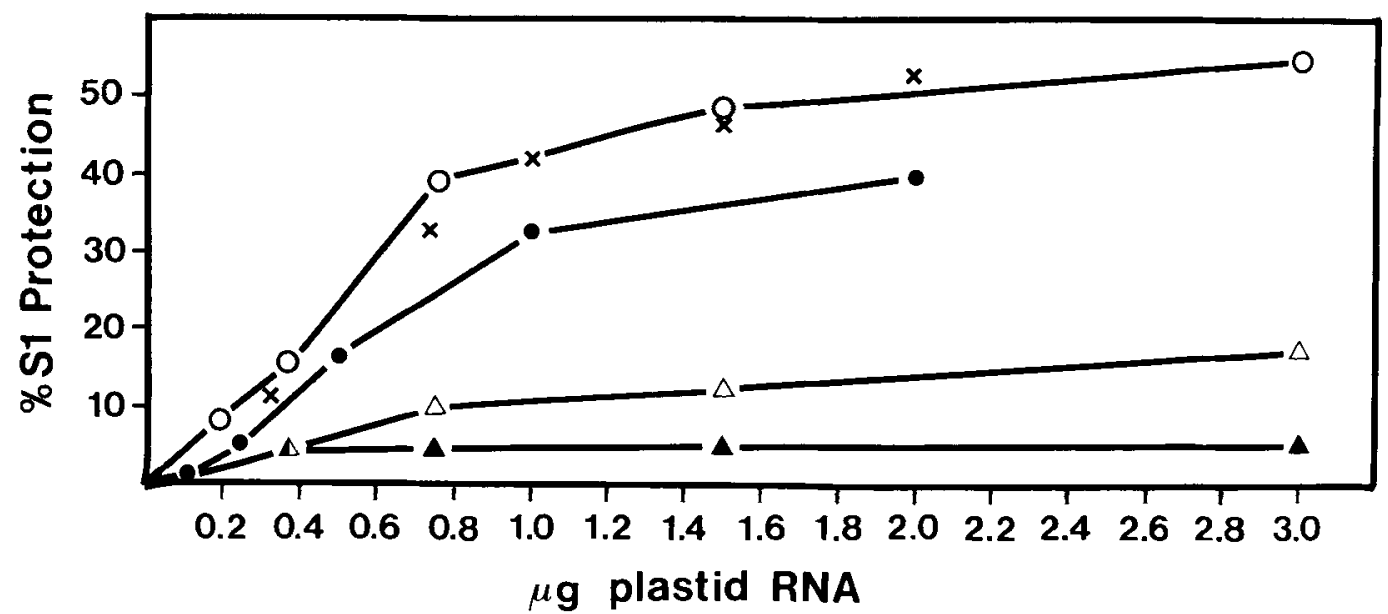

Figure 7. Protection from S1-nuclease degradation of the 242 base "Dark" primer (circles) and the 195 base "Light" primer (triangles) after hybridization to plastid RNA from dark grown seedlings (filled symbols) and from greened seedlings (open symbols). The $\mathrm{X}$ symbols result from summation of points on the open triangle curve and the closed circle curve. The values for S1-nuclease protection employing the 242 base primer were corrected for the SI-nuclease dependent reduction in size (cf. Figure 5). Values for S1-nuclease protection in controls employing no RNA was subtracted from the values obtained with RNA.

as a function of RNA concentration in the hybridizations is depicted in Figure 7. The downstream 242 base "Dark" probe is protected to a greater extent by the rbcL mRNAs than is the upstream 195 base "Light" probe. As expected, the latter is hardly protected by the short rbcL transcript of the RNA in dark grown seedlings. Close to $20 \%$ of this probe is protected by $3 \mu \mathrm{g}$ of RNA from the greened seedlings. The degree of protection obtained with the "Dark" probe hybridized to RNA from greened seedlings is close to the sum of the values for the "Dark" probe hybridized to RNA from dark grown seedlings and those for the "Light" probe hybridized to the RNA of the greened seedlings. A net increase of the rbcL mRNA thus takes place upon illumination of dark grown seedlings. From the lower linear part of the two curves obtained with the "Dark" probe the amount of mRNA synthesized can be estimated. Twentyfive percent of S1-nuclease protection is obtained when $0.5 \mu \mathrm{g} \mathrm{RNA}$ of the illuminated seedlings is used, whereas $0.8 \mu \mathrm{g}$ of RNA from dark grown seedlings is required to achieve the same protection. This corresponds to a net increase in S1-nuclease protection by $60 \%$. This increase in the content of LS mRNA occurs over a period of eight hours of greening of six days old barley seedlings. The $25 \%$ protection corresponds to about $0.018 \mathrm{pmol}$ of the full length probe. Assuming that this equals the amount of LS mRNA in the two experiments and that the average length of the two transcripts is 1750 nucleotides, one will expect $11 \mathrm{ng}$ of LS mRNA molecules per $0.5 \mu \mathrm{g}$ of plastid RNA after illumination and $11 \mathrm{ng}$ per $0.8 \mu \mathrm{g}$ of plastid RNA before illumination. Thus, it appears that the LS mRNA amounts to $2.20 \%$ of the RNA in plastids of greened seedlings and $1.38 \%$ of the RNA in plastids of dark grown seedlings.

The increase in LS mRNA upon illumination is not solely caused by the accumulation of the longer transcripts. The degree of protection afforded the probes by the two types of RNA indicates that about $20 \%$ of the total LS mRNA after illumination consists of the longer transcript. The total increase of the LS mRNA during illumination amounts to $37.5 \%$ of this mRNA present after greening. The difference of $17.5 \%$ is therefore due to the increase in the amount of the short transcript.

S1-nuclease protection values do not reach $100 \%$ with the employed amounts of plastid RNA. This results from suboptimal concentra- 
tions of the hybridizing molecular species and insufficient hybridization time. At low RNA concentrations a linear relationship is achieved, while at higher RNA concentration competition between the many RNA molecules might decrease the efficiency of full length hybridization to the DNA probe and subsequent S1-nuclease protection. The increase in LS mRNA can account for the increase in RuBPCase-Oase upon illumination of dark grown barley seedlings, as measured by KANNANGARA (13).

\section{DISCUSSION}

\subsection{The promotor region of higher plant rbcL genes}

In this section the nucleotide sequences upstream of the $\mathrm{ATG}^{\mathrm{Mct}}$ start triplet of the rbcL reading frames of four higher plant species together with the available data for transcript 5 ' ends are compared. Sequence data are also available for three cyanobacterial genes $(6,24$, 28 ) and one green alga species, Chlamydomonas reinhardii (7). However, the sequence homology with the higher plants upstream from the rbcL reading frames of these four genes is scant and they are therefore excluded from the discussion. Furthermore, two transcript 5 ' end have been determined only for $C$. reinhardii, and these cannot be related to those found in the higher plants. In Figure 2 the nucleotide sequences of about 450 bps upstream from the ATG codon in the barley and maize (17) genes aligned with the corresponding nucleotide sequences of the spinach (35) and tobacco (27) genes. Gaps have been introduced into the spinach and tobacco sequences to maximize homology. Part of the sequence information is derived from available data on the atp $B$ sequences from maize, spinach and tobacco $(15,26,34,35$, dr. J. Mullet, dr. E. Orozco and Professor N. -H. ChUA, personal commun.). The HincIl site at the onset of the depicted sequences have been found to be in the putative "-35" promotor region of the spinach and maize atpB genes. It is likely that this HincII site of barley and tobacco is also in the atpB promotor region. Thereby, the complete region between the two genes in the four species would be included in the sequences presented.
The two barley rbcL transcript 5' ends are located at position -58 for the short transcript and at -316 for the long one (cf. section 3.3). In maize, an rbcL transcript 5 ' end was located at -65 , i. e. seven nucleotides further upstream in a region of the maize gene which is highly homologous to the barley sequence. In spinach and tobacco the S' ends were found at $-177 /-178$ and at -182 , respectively. This region of the spinach and tobacco genes is highly homologous to the barley sequence around $\mathbf{- 3 2 0}$. The homology also extends to the maize sequence around -300 .

Two rbcL RNAs have recently also been found in spinach and maize (dr. J. MULLET, dr. E. OROzCO and Professor N.-H. CHUA, personal commun. ), and these are comparable to those of barley with regard to their 5 ' ends. In spinach, a short transcript (-65) was identified and in maize a long transcript was found (-305). Thus, the expression of $\mathrm{rbcL}$ genes in spinach and maize shares features with that of the barley gene. It will be of interest to see whether the two transtripts are also present in tobacco and other higher plants. The data from Northern hybridizations of wheat and pea plastid RNA with rbcL sequences have sofar not given an indication of their presence $(14,29)$. In the two barley rbcL transcripts the end point of the longer one is four nucleotides short of the comparable ones in spinach and tobacco and that of the shorter transcript is seven nuclotides short of the end point identified in maize.

It appears that the four sequences shown in Figure 2 can be divided into four domains. Using the numbering of the barley sequence as a reference and starting at the ATG the four domains reveal the following characteristics: a) In the region -1 to -83 the sequences are highly homologous, contain the putative ribosome binding site at -5 to -11 and the 5' end of the short transcript. The close conservation indicates the presence of other sequences which are important for translation of the mRNA. b) The region -84 to -279 distinguishes the two monocotyledons from the two dicotyledons by the deletion of about 140 bases in the latter. Furthermore, the sequence homology is less pronounced than in the first described domain. It is not possible to find sub-sequences which are shared between the four genes and which look like the consensus 
sequences of the known types of promotor signals ("-10" box, "-35" box, "Hogness" box) for transcription initiation $(12,31)$. This leaves the question whether transcription of the short mRNA molecules can be initiated at -65 an open one. The third domain c) is the region from -279 to -359 . A very high degree of homology among the four species is encountered here. The position of the 5' ends of the larger rbcL transcripts are also conserved. Further, potential attenuator signals of prokaryote type (12) in the form of short inverted repeats can be found immediately downstream from the 5' end of the transcripts (27). The 40 nucleotides upstream thereof contain the prokaryotic type transcription initiation signals, the "-10" and "-35" boxes. There are 18 nucleotides between the two signals. In bacterial genes 16 to 18 nucleotides are commonly found between the "-10" and "-35" regions (12, 31). A distance of 18 bases has also been found between the two signals in other chloroplast genes, i. e. in atpB of maize (15) and psbA of spinach and Nicotiana debneyi (33), whereas different structures in putative promotor regions have been suggested for other chloroplast genes (30). The fourth domain d) is the intergenic region between the rbcL gene and the atpB gene. It spans from -359 in the barley sequence and the putative "-35" box of the atpB genes. There is very little homology in the intergenic region. This suggests that none of the sequences in this domain are of importance for transcription of the two genes, i. e. the rbcL genes contain all the information which is necessary for its transcription downstream from -359 (barley numbering). Employing spinach chloroplast RNA polymerase, GRUISSEM et al. (10) showed that DNA sequenees between positions -56 and -85 upstream from spinach and Euglena gracilis tRNA genes are required for maximal expression in an in vitro transcription assay.

\subsection{The light-induced expression of rbcL genes}

I have previously observed that the amount of RNA found in plastids of barley seedlings greening over short periods of time does not change dramatically. At the same time there is no major increase in the amount of leaf dry matter. I have therefore considered it possible to use the plastid
rRNAs, which contribute close to $90 \%$ of the plastid RNA, as an internal standard for the measurement of quantitative changes of certain transcripts derived from genes encoded by the the chloroplast genome (22). The mRNA encoding the large subunit of RuBPCase-Oase is among these transcripts. In the work presented here it has been shown that illumination of dark grown seedlings for eight hours with white light leads to a net increase of $60 \%$ in the amount of LS mRNA, as measured by hybridization with specific DNA probes. It is possible that the LS mRNA is found exclusively as a truncated RNA species in plastids of dark grown seedlings 6 days of age and older. Upon illumination this transcript is persistent but a transcript which is 258 nucleotides longer at the 5' end, accounts for a major fraction of the quantitative increase. On the DNA sequence level this transcript is the one that is preceded by bacterial type promotor sequences, whereas this is not the case for the short transcript. Under the same growth conditions $(13,22)$ the net increase of RuBPCase-Oase protein in barley is slightly higher, about 80 $100 \%(13,29)$, as compared to the increase of $60 \%$ in the amount LS mRNA. This suggests that the longer transcript might be translated more efficiently than the short one, based on the assumption that this transcript is indeed to be found in organello of the living plant.

The relative increase in expression of the $r b c L$ gene must be associated with a corresponding increase in expression of the nuclear gene for the small subunit of the enzyme or an increase in translation of its mRNA. It has been demonstrated that the pea small subunit gene is indeed transcribed at highly induced levels upon illumination (29). Also, the general effect of light on transcription of the rbcL gene in pea plants grown in a dark-light cycle was significantly more pronounced than the effect of illumination of dark grown barley seedlings. However, in both cases it can be concluded that the transcription of the genes involved in the biosynthesis of the enzyme is positively effected by light and that these events can be included among the set of reactions occurring during light induced plastid development, which are under the control of the phytochrome system.

The finding of two transcripts from the rbcL 
gene in more than one plant species leads to a number of questions. Is the gene transcribed from two different promotors like some developmentally induced bacterial genes (31)? Are the two transcripts the result of the function of two distinctively different RNA polymerases, or is the short transcript a breakdown product of the larger due to some developmentally regulated reaction? Clues to the answer of these questions can be obtained from the sequences. It does appear suggestive that the 20 nucleotides upstream from $-65 \mathrm{i}$. e. beyond the end point of the short transcript are closely conserved among the four species studied (Figure 2). Is this a signal for a specific degradation process which is occurring when low rates of LS synthesis is advantageous? Another question concerns the function of the extra 140 nucleotides contained in the long transcript of the barley and maize genes. The homology between the barley and maize sequences is quite high in this region which makes it a candidate for signals responsible for the differences observed in the light induced regulation of the enzyme in mono- and dicotyledons.

In the C4 plant maize LS mRNA and RuBPCase-Oase are found only in the plastids of bundle sheath cells and not in the mesophyll cells (16) as is the case in barley. This means that the maize genes must be under the control of a tissue specific regulatory mechanism. If signals for this regulation are present in the sequence upstream of the ATG codon they must be sought among the relatively small differences distinguishing the barley and maize gene.

\section{ACKNOWLEDGEMENTS}

I am indebted to dr. J. Mullet, dr. E. Orozco and Professor N. -H. CHUA for communication of unpublished results. Further, dr. S. HolmberG and Ms. L. HANLEY-BOWDOIN are thanked for discussion and valuable suggestions. Professor D. von WeTtstein and dr. R. OLIVER are thanked for critical reading the manuscript.

\section{REFERENCES}

1. Berk. A. J. \& P. A. Sharp: Spliced early mRNAs of Simian Virus 40. Proc. Natl. Acad. Sci. USA 75, 1274-1278 (1978)

2. Birnboim. H. C. \& J. Doly: A rapid alkaline extraction procedure for screening recombinant plasmid DNA. Nucl. Acids Res. 7, 1513 -1520 (1979)

3. Bloom, M. V. , P. Milos \& H. Roy: Light-dependent assembly of ribulose-1,5-bisphosphate carboxylase. Proc. Natl. Acad. Sci. USA 80, 1013-1017 (1983)

4. Chua. N. -H \& G. W. Schmidt: Post-translational transport into intact chloroplast of a precursor to the small subunit of ribulose-1,5-bisphosphate carboxylase. Proc. Natl. Acad. Aci. USA 75, 6110 6114 (1978)

5. Coruzzi, G. . R. Broglie, G. Lamppa \& N. -H. CHuA: Expression of nuclear genes encoding the small subunit of ribulose-1,5-bisphosphate carboxylase. In: Structure and function of plant genomes. O. Ciferri \& L. Dure III, eds. pp. 47-59. Plenum Press, New York and London (1983)

6. CuRtis. S E \& R. HASELKORN: Isolation and sequence of the gene for the large subunit of ribulose1,5-bisphosphate carboxylase from the cyanobacterium Anabaena 7120. Proc. Natl. Acad. Sci. USA 80, 1835-1839 (1983)

7. Dron. M.. M.RahiRE\& J. -D. RochalX: Sequence of the chloroplast DNA region of Chlamydomonas reinhardii containing the gene of the large subunit of ribulose bisphosphate carboxylase and parts of its flanking regions. J. Mol. Biol 162, 775-703 (1982)

8. Dunsmuir. P. \& J. Bedbrook: Chlorophyll A/B binding proteins and the small subunit of ribulose bisphosphate carboxylase are encoded by multiple genes in Petunia. In: Structure and function of plant genomes. O. Ciferri \& L. Dure III, eds. pp. 221-230. Plenum Press, New York and London (1983)

9. Ghosh. P. K. V. B. Reddy, J. Swinscoe, P. LeboWITZ \& S. M. WEISSMAN: Heterogeneity and 5'-terminal structures of the late RNAs of Simian Virus 40. J. Mol. Biol. 126, 813-846 (1978)

10. Gruissem, W. B. M. GreenberG. G. Zurawski. D. M. Prescott \& R. B. Hallick: Biosynthesis of chloroplast transfer RNA in a spinach chloroplast transcription system. Cell 35, 81 5-828 (1983)

11. Hu.N. -T. \& J.Messing: The making of strand-specific M13 probes. Gene 17, 271-277 (1982)

12. Jaurin, B. , T. Grundstrom, T. Edlund \& S. NORMARK: The E. coli $\beta$-lactamase attenuator mediates growth rate-dependent regulation. Nature $290,221-225$ (1981) 
13. Kannangara. C. G.: The formation of ribulose diphosphate carboxylase protein during chloroplast development in barley. Plant Physiol. 44, 1553-1537 (1969)

14. Koller, B. . H. Delius \& T. Dyer: The organization of the chloroplast DNA in wheat and maize in the region encoding the LS gene. Eur. J. Biochem. 122, 17-23 (1982)

15. Krebbers. E. T. I M. Larrinua, L. Mcintosh \& L. BOGORAD: The maize chloroplast genes for the $\boldsymbol{\beta}$-and $\varepsilon$-subunits of the photosynthetic coupling factor $\mathrm{CF}_{1}$ are fused. Nucl. Acids Res. 10, 4985-5002 (1982)

16. Link. G. \& L. Bogorad: Sizes, locations and directions of transcription of two genes on a cloned maize chloroplast DNA fragment. Proc. Natl. Acad. Sci. 77, $1832-1836$ (1980)

17. MCIntosh. L. C. Poulsen \& L. Bogorad: Chloroplast gene sequence for the large subunit of ribulose bisphosphate carboxylase of maize. Nature 288, 556-560 (1980)

18. MESSING. J.\& J. VIEIRA: A new pair of M13 vectors for selecting either DNA strand of double-digest restriction fragments. Gene 19, 269-276 (1982)

19. Mishkind, M. L. \& G.W. Schmidt: Posttranscriptional regulation of ribulose 1,5-bisphosphate carboxylase small subunit accumulation in Chlamydomonas reinhardtii. Plant Physiol. 72, 847-854 (1983)

20. Miziorko, H \& G. H. LoRimer: Ribulose-1,5-bisphosphate carboxylase-oxygenase. Ann. Rev. Biochem. 52, 507-535 (1983)

21. Poulsen, C.: Comments on the structure and function of the large subunit of the enzyme ribulose bisphosphate carboxylase-oxygenase. Carlsberg Res. Commun. 46, 259-278 (1981)

22. POULSEN. C.: The barley chloroplast genome: Physical structure and transcriptional activity in vivo. Carlsberg Res. Commun. 48, 57-80 (1983)

23. Rasmussen.S. . H. E. Hopp \& A. BRandT: Nucleotide sequences of cDNA clones for $B \perp$ hordein polypeptides. Carlsberg Res. Commun. 48, 187 199 (1983)

24. REICHELT. B. Y.\& S. F. Delaney: The nucleotide sequence for the large subunit of ribulose 1,5-bisphosphate carboxylase from a unicellular cyanobacterium, Synechococcus PCC6301. DNA 2, 121-129 (1983)

25. Sanger, F. S. Nicklen \& A. R. Coulson: DNA sequencing with chain-terminating inhibitors. Proc. Natl. Acad. Sci. USA 74, 5463-5467 (1977)
26. Shinozaki, K. \& M. Sugiura: Sequence of the intercistronic region between the ribulose-1,5-bisphosphate carboxylase/oxygenase large subunit and the coupling factor $\beta$ subunitgene. Nucl. Acids Res. 10, 4923-4934 (1982)

27. Shinozaki, K. \& M. Sugiura: The nucleotide sequence of the tobacco chloroplast gene for the large subunit ribulose-1,5-bisphosphate carboxylase/oxygenase. Gene 20, 91-102 (1982)

28. Shinozaki. K. . C. Yamada. N. Takahata \& M. SugIURA: Molecular cloning and sequence analysis of the cyanobacterial gene for the large subunit of ribulose-bisphosphate carboxylase/oxygenase. Proc. Natl. Acad. Sci. USA 80, 4050-4054 (1983)

29. SMITH, S. M. \& R. J. ElLIS: Light-stimulated accumulation of transcripts of nuclear and chloroplast genes for ribulosebisphosphate carboxylase. J. Mol. Appl. Genet. 1, 127-137 (1981)

30. Steinmetz, A. A. . E. T. Krebbers, Z. Schwarz. E. J. GubBins \& L. Bogorad: Nucleotide sequences of five maize chloroplast transfer RNA genes and their flanking regions. J. Biol. Chem. 258, 5503-5511 (1983)

31. van den Putte, E. A. R. H. Geerse. H. PanneKOEK \& P. VAN DEN PUTTE: In vivo transcription of the E. coli uvrB gene: both promotors are inducible by UV. Nucl. Acids Res. 11, 4355-4363 (1983)

32. Zinder. N. D. \& J. D. BOEKE: The filamentous phage (Ff) as vectors for recombinant DNA - a review. Gene 19, 1-10 (1982)

33. Zurawski, G. , H. J. Bohnert, P. R. Whitfeld \& W. Bottomley: Nucleotide sequence of the gene for the $M, 32,000$ thylakoid membrane protein from Spinacia oleracea and Nicotiana debneyi predicts a totally conserved primary translation product of $M_{r} 38,950$. Proc. Natl. Acad. Sci. USA 79, $7699-7703$ (1982)

34. Zurawski, G. , W. Bottomley \& P. Whitfeld: Structures of the genes for the $\beta$ - and $\varepsilon$-subunits of spinach chloroplast ATPase indicate a dicistronic mRNA and an overlapping translation stop/ start signal. Proc. Natl. Acad. Sci. USA 79, 62606264 (1982)

35. Zurawski. G. . B. Perrot, W. Bottomley \& P. R. WHITFELD: The structure of the gene for the large subunit of ribulose 1,5-bisphosphate carboxylase from spinach chloroplast DNA. Nucl. Acids Res. 9, 3251-3271 (1981) 